
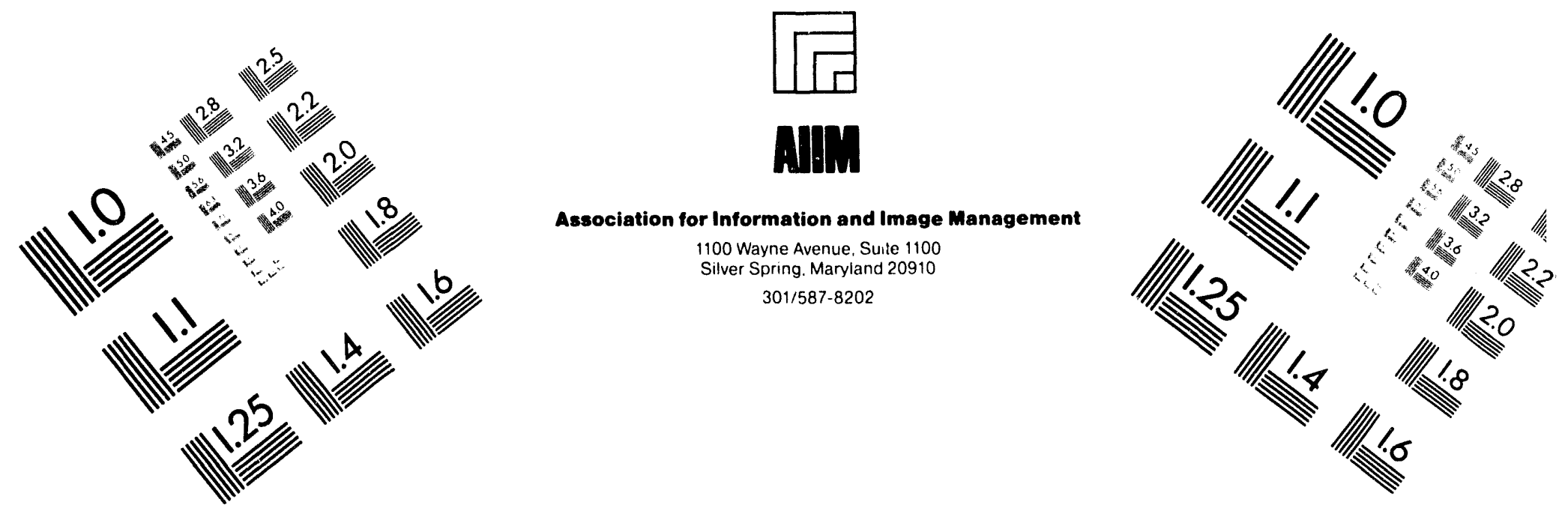

\title{
Centimeter
}

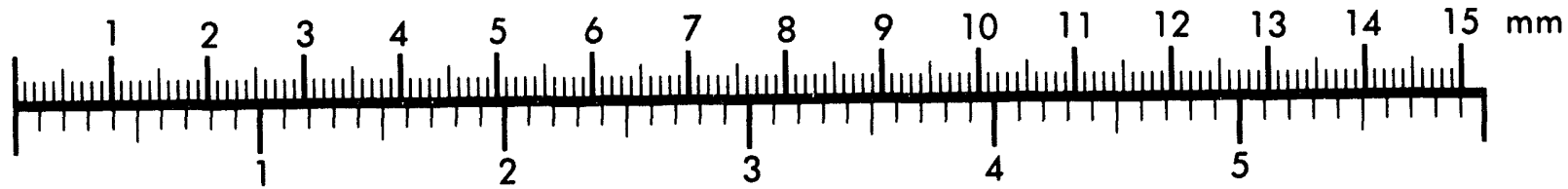
Inches
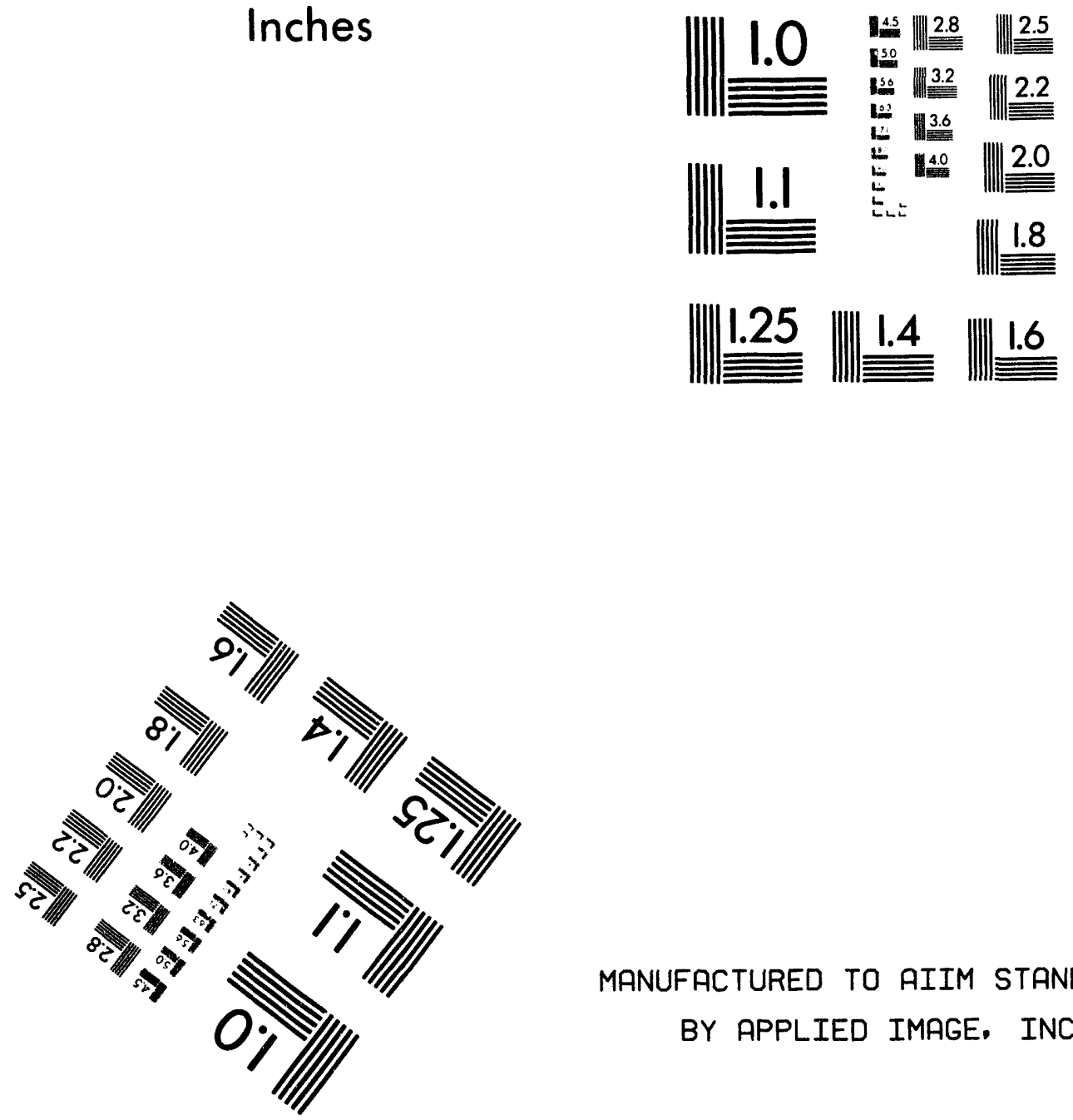

MANUFACTURED TO AIIM STANDARDS

BY APPLIED IMAGE, INC.

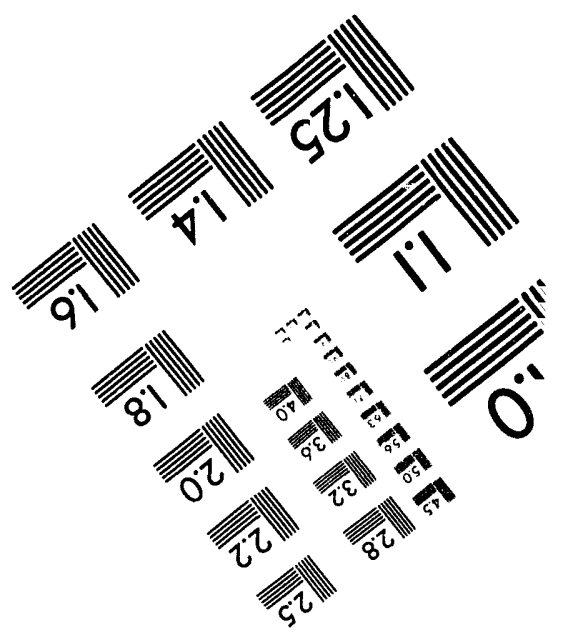


$$
=
$$
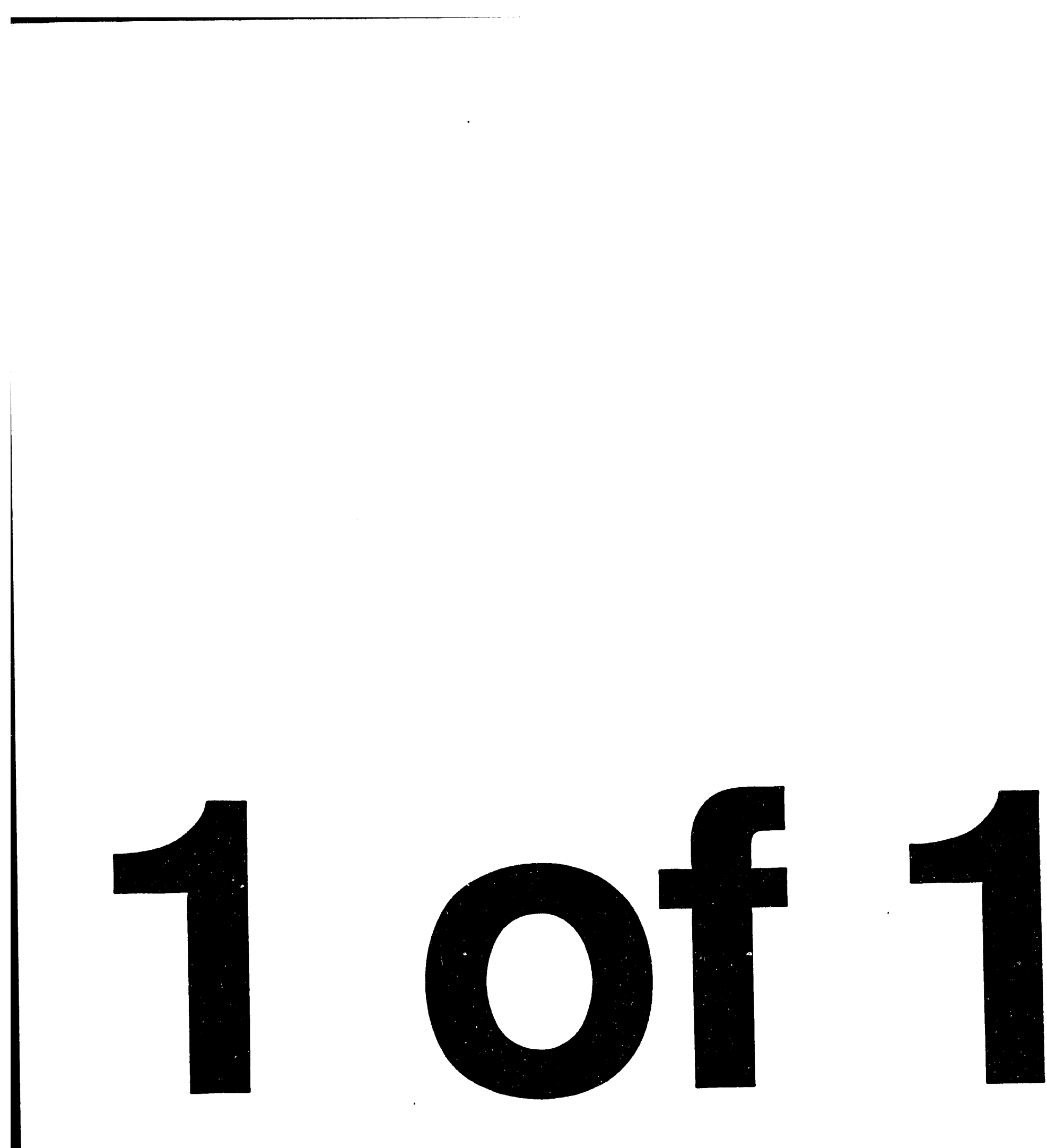

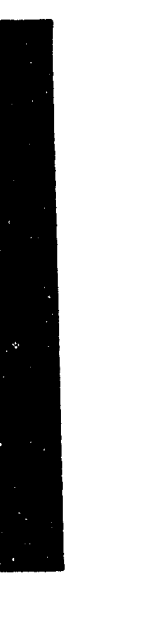




\title{
Conf- $940635--4$
}

GA-A21737

\section{THE EFFECT OF \\ THE EDGE CURRENT DENSITY \\ ON CONFINEMENT AND \\ KINK MODE STABILITY IN \\ H-MODE AND VH-MODE DISCHARGES}

by

J.R. FERRON, L.L. LAO, T.H. OSBORNE,

O. SAUTER,* E.J. STRAIT, T.S. TAYLOR,

S.J. THOMPSON, and A.D. TURNBULL

This is a preprint of a paper to be presented at the 21st EPS Conference on Controlled Fusion and Plasma Physics, June 27-July 1, Montpellier, France, and to be printed in the Proceedings.

\author{
Work supported by \\ U.S. Department of Energy \\ Contract DE-AC03-89ER51114
}

*EPFL/Ecole Polytechnique Fédérale de Lausanne

GENERAL ATOMICS PROJECT 3466

JULY 1994 


\section{DISCLAIMER}

This report was prepared as an account of work sponsored by an agency of the United States Government. Neither the United States Government nor any agency thereof, nor any of their employees, makes any warranty, express or implied, or assumes any legal liability or responsibility for the accuracy, completeness, or usefulness of any information, apparatus, product, or process disclosed, or represents that its use would not infringe privately owned rights. Reference herein to any specific commercial product, process, or service by trade name, trademark, manufacturer, or otherwise, does not necessarily constitute or imply its endorsement, recommendation, or favoring by the United States Government or any agency thereof. The views and opinions of authors expressed herein do not necessarily state or reflect those of the United States Government or any agency thereof. 


\title{
THE EFFECT OF THE EDGE CURRENT DENSITY ON CONFINEMENT AND KINK MODE STABILITY IN H-MODE AND VH-MODE DISCHARGES*
}

\author{
J.R. Ferron, L.L. Lao, T.H. Osborne, O. Sauter, ${ }^{\dagger}$ E.J. Strait, \\ T.S. T.YLOR, S.J. ThOMPSON, and A.D. TURNBULL \\ General Atomics, San Diego, California, U.S.A.
}

Abstract. The effect of the local current density in the outer portion of a tokamak discharge $[J(\rho \approx a)]$ is discussed in three situations. In an H-mode discharge, a strong reduction of $J(\rho \approx a)$ results in the loss of the H-mode pressure pedestal. A smaller reduction in $J(\rho \approx a)$ can prevent the transition from $\mathrm{H}$-mode to VH-mode. Finally, a sufficiently large value of $J(\rho \approx a)$ accompanied by a sufficiently large value of the pressure gradient in the same region of the discharge, can destabilize low- $n$ (e.g., $n=1$ to 5) kink-type modes in a VH-mode discharge.

The global shape of the current profile in a tokamak discharge, as characterized by the internal inductance $\left(\ell_{i}\right)$, has previously been shown $[1,2]$ to affect both the energy confinement and the maximum achievable value of beta determined by ideal MHD stability. As $\ell_{i}$ is increased, the energy confinement time increases in both $\mathrm{L}$-mode and $\mathrm{H}$-mode discharges $[1,2]$, and the beta limit set by both low- $n$ kink-type instabilities [3] and high- $n$ ballooning instabilities [4] increases. In order to find the current profile that optimizes confinement and beta simultaneously, it is also necessary to understand the effects of varying the local current density, as opposed to the global profile shape. This paper discusses the effect of the local current density in the outer portion of the discharge $[J(\rho \approx a)]$ in the DIII-D tokamak in three situations: (a) in H-mode discharges, a strong reduction of $J(\rho \approx a)$ results in the loss of the pressure pedestal that is characteristic of H-mode and a corresponding loss of approximately $1 / 2$ of the stored energy, (b) a less significant reduction in $J(\rho \approx a)$ can prevent the transition from $\mathrm{H}$-mode to VH-mode, and (c) a sufficiently large value of $J(\rho \approx a)$ accompanied by a sufficiently large value of the pressure gradient in the same region of the discharge $\left[P^{\prime}(\rho \approx a)\right]$ can destabilize low-n (e.g., $n=1$ to 5$)$ kink-type modes in a VH-mode discharge resulting in a significant loss of stored energy and a return to H-mode.

The evidence for a correlation between the edge current density and confinement comes from two sets of experiments in which a negative current ramp is used to reduce $J(\rho \approx a)$ and increase $\ell_{i}$, one in an ELMing $H$-mode discharge and one in VH-mode discharges. In the first case a rapid negative current ramp $(-2 \mathrm{MA} / \mathrm{sec})$ was initiated after the discharge reached the period of continuous, giant ELMs, as shown in Fig. 1. During the current ramp, the stored energy was observed to decrease simultaneously with the decrease in plasma current so that confinement normalized to $I_{\mathrm{p}}$ was approximately constant and near the value consistent with the JET/DIII-D scaling relation [1] for H-mode confinement [Fig. 1(d)].

The significant change observed in this ELMing H-mode discharge during the current ramp is the loss of the edge pressure pedestal, as illustrated in Fig. 2. Just before the current ramp (2800 msec), the temperature and density profiles are typical of $\mathrm{H}$-mode, with large gradients in density and temperature near the discharge edge. Just after the current ramp (3150 msec), the edge electron density is much lower and the electron temperature pedestal is eliminated. Because the volume in the outer portion of the discharge is large, the edge pressure pedestal contains approximately half of the stored energy in the discharge, about the same fraction as is lost during the current ramp.

The presence of the pressure pedestal normally accounts for the difference between L-mode and H-mode confinement, so without the pedestal, L-mode confinement levels would be expected. However, in this case the confinement is still at the H-mode level. This observation

*This is a report of work sponsored by the U.S. Department of Energy under Contract No. DE-AC03-89ER51114 and by the Swiss National Science Foundation.

†CRPP/Ecole Polytechnique Fédérale de Lausanne. 


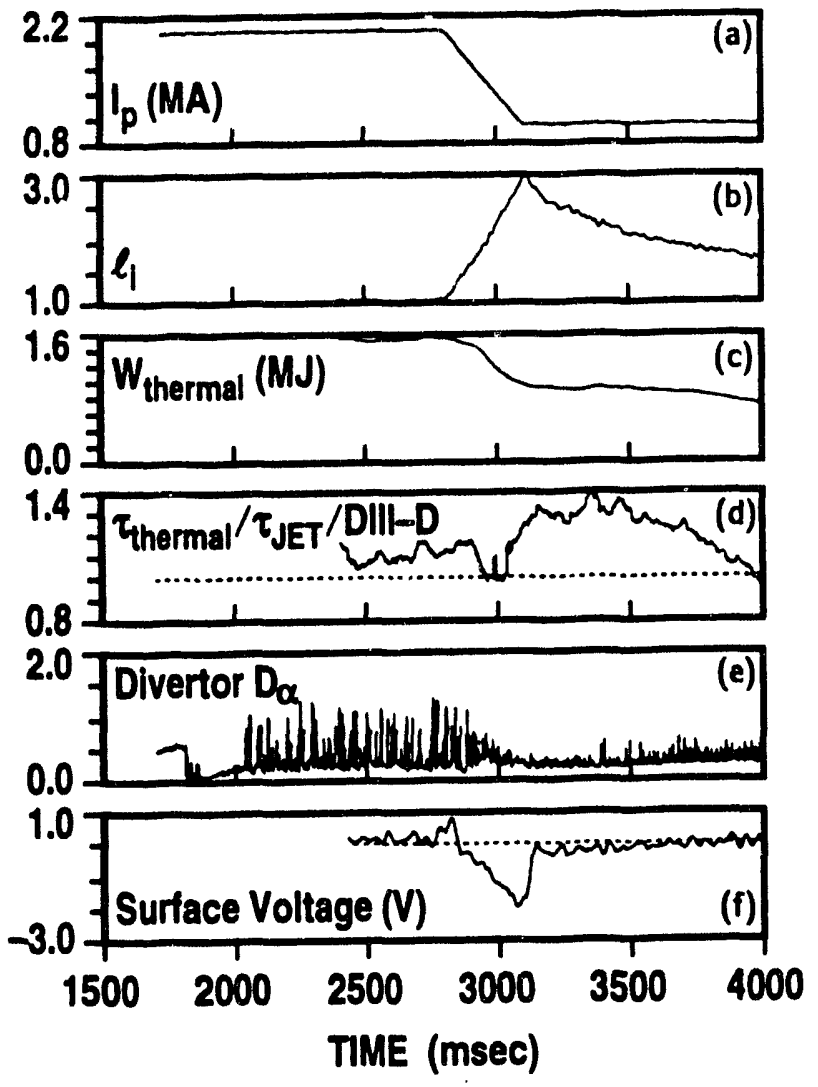

Fig. 1. Time evolution of an $\mathrm{H}$-mode discharge with a rapid current ramp.
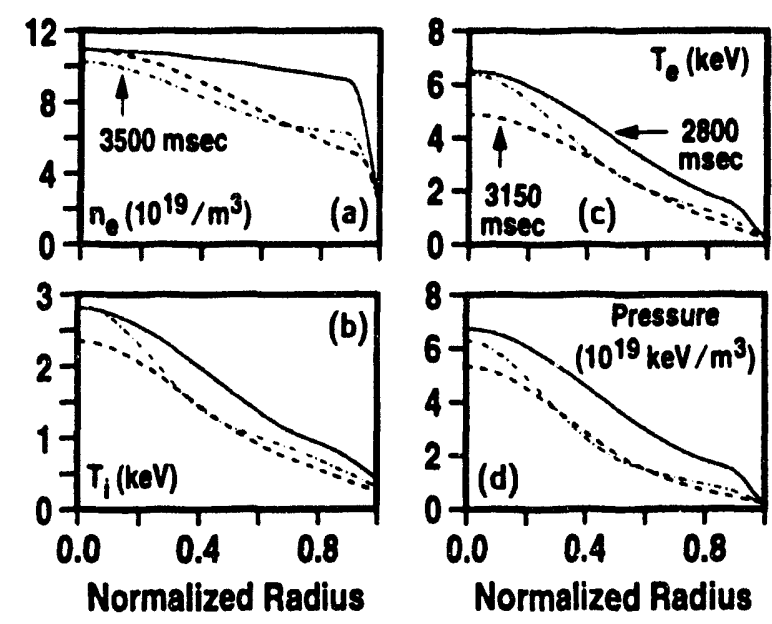

Fig. 2. Radial profiles of parameters for the discharge in Fig. 1. is consistent with the expected effect of the large increase in $\ell_{i}$ [Fig. 1 (b)] during the current ramp, which is an increase in the normalized confinement.

The difference between this discharge and other $\mathrm{H}$-mode discharges with increased $\ell_{i}[1,2]$ is the larger current ramp rate which produces a larger negative surface voltage than in the previous experiments. This difference suggests that the loss of the $\mathrm{H}$-mode pressure pedestal is correlated with the negative surface voltage or, al ternatively, the negative edge current density driven by the negative surface voltage. The discharge does not loose all of the characteristics of $\mathrm{H}$-mode, however. The low divertor $\mathrm{D}_{\alpha}$ radiation level reached after the transition from $\mathrm{L}$-mode to $\mathrm{H}$-mode remains. The ELM frequency decreases significantly during the current ramp, probably because of the decrease in edge pressure gradient, but there are still some intermittent $D_{\alpha}$ spikes that are typical of ELMs. After the surface voltage [Fig. 1 (f)] returns to a level near zero there are indications that the $\mathrm{H}$-mode confinement is returning: the normalized confinement increases [Fig. 1(d)], the local effective thermal diffusivity decreases (e.g., by $80 \%$ at $\rho$ $=0.8$ ), and the edge density and the temperatures begin to increase (Fig. 2, $3500 \mathrm{msec}$ ). There is loss of $\mathrm{H}$-mode confinement after $4000 \mathrm{msec}$ when the discharge shape changes from double-null divertor toward a singlenull divertor with $X$-point at the top, thus raising the $\mathrm{H}$-mode power threshold. The confinement decreases below the JET/ DIII-D level and the divertor $D_{\alpha}$ level increases.

The use of a negative current ramp can prevent the transition from $\mathrm{H}$-mode to the improved confinement regime of $\mathrm{VH}$-mode [5], as shown here through a comparison of three discharges. The line $A$ in Fig. 3 shows the time evolution of a typical $\mathrm{VH}$-mode discharge in which the energy confinement time peaks at 3.2 times the value expected

from the ITER89-P L-mode scaling relation [1]. The discharge makes a transition from H-mode to VH-mode when there is a spontaneous increase in the radial gradient of the toroidal rotation velocity, indicatirig an increase in the gradient of the radial electric field which is strongly correlated with reduced fluctuation levels and improved confinement [5]. The increase in the electric field gradient and the reduction in transport occurs primarily in the outer portion of the discharge, $r / a>0.6$. The line $B$ in Fig. 3 shows a discharge with a relatively slow current ramp $(-0.5 \mathrm{MA} / \mathrm{sec})$ that begins before the transition to $\mathrm{H}$-mode and $\mathrm{VH}$-mode. In this discharge the 

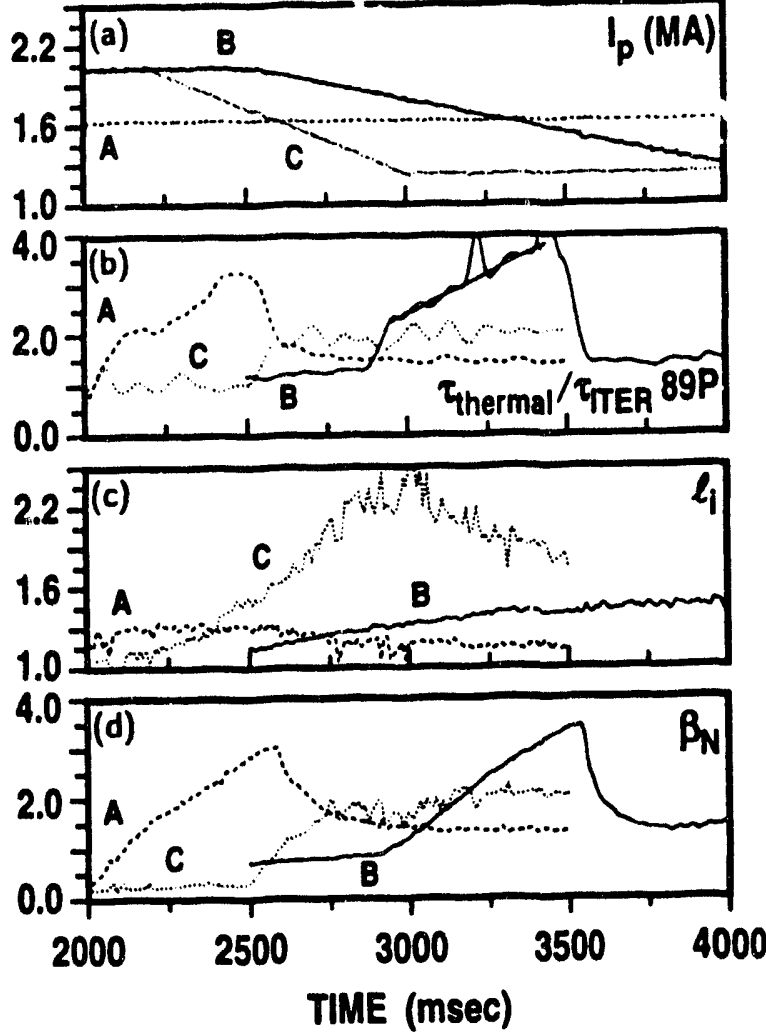

Fig. 3. Time evolution of a standard VHmode discharge (line $\mathrm{A}$ ), a VH-mode during a current ramp (line B), and a discharge with a current ramp that remained in H-mode (line C). current ramp results in an increase in $\ell_{i}$ that can account for confinement that is improved over the standard $\mathrm{VH}$-mode discharge to 3.8 times the ITER89-P value. However, in the discharge represented by line $\mathrm{C}$, there is a relatively rapid current ramp (-1 MA/sec) begun before the $\mathrm{H}$-mode transition and there is no transition into VH-mode, although very similar discharges without a current ramp did have the $\mathrm{VH}$-mode transition and discharges with a similar current ramp begun after the $\mathrm{VH}$-mode transition remain in $\mathrm{VH}$-mode. The current ramp apparently prevents the $\mathrm{VH}$-mode transition. This may happen because the current profile is modified by the negative surface voltage associated with the current ramp primarily in the region where the increase in the radial electric field gradient that is characteristic of VH-mode is expected to occur.

The period of enhanced confinement in VH-mode discharges is usually ended by what is believed to be a low-n ( 1 to 5 ), external, kink-type mode $[6,7]$. This mode is unstable at a wide range of values of normalized beta, $\beta_{\mathrm{N}}=\beta /(I / a B)$. A study of a database containing many DIII-D VH-mode discharges shows that discharges which have the typical sharp drop in stored energy at the termination of the VH-mode period,

indicating the presence of the low- $n$ instability, have a peak value of $\beta_{\mathrm{N}}$ that varies between 2.4 and 4.0. The peak value increases with the input neutral beam power. These data indicate that the typical VH-mode termination does not depend on reaching a specfic value of $\beta_{\mathrm{N}}$.

Rather than depending on a specific value of $\beta_{\mathrm{N}}$, the VH-mode termination is triggered primarily by large values of current density and pressure gradient near the discharge edge $[6,7]$. In a VH-mode discharge, the edge current density is significant because bootstrap current accompanies the large edge pressure gradient. In the experiment, the operating regime can be varied by changing $\beta_{N}$, the edge current density, the edge pressure gradient, and $\ell_{i}$ in a manner consistent with kink mode stability. For example, increasing the neutral beam power increases the rate of increase of the total stored energy compared to the rate of increase of $P^{\prime}(\rho \approx a)$ and $J(\rho \approx a)$ and produces higher pressure on axis, allowing larger values of $\beta_{N}$ to be reached before instability occurs.

The parameters of the reconstructed equilibria are consistent with the stability boundaries predicted by numerical calculations using the linear, ideal MHD staility code GATO. For instance, Table I compares three discharges, a "standard" VH-mode discharge [7], a "high $\ell_{i}$ " discharge and a "high power" discharge. The standard discharge has relatively high values of $P^{\prime}(\rho \approx a)$ and $J(\rho \approx a)$, but a lower value of $\ell_{\mathrm{i}}$. GATO calculations show that increasing $\ell_{\mathrm{i}}$ above the value of the standard discharge with $P^{\prime}(\rho \approx a)$ and $J(\rho \approx a)$ unchanged increases the instability growth rate [7]. The high $\ell_{i}$ discharge, however, was stable because the value of $J(\rho \approx a)$ was reduced by a factor of 7 . The discharge with the high neutral beam input power reached $\beta_{\mathrm{N}}=4$ compared to $\beta_{\mathrm{N}}=3.4$ for the standard discharge because both $J(\rho \approx a)$ and $P^{\prime}(\rho \approx a)$ are slightly lower than the values in the standard discharge. 
Table I: Comparison of Parameters at the VH-mode Termination

\begin{tabular}{lccl}
\hline & $P^{\prime}(r / a \approx 1)(\mathrm{Pa})$ & $J(r / a \approx 0.95) /\langle J\rangle$ & $\ell_{\mathrm{i}}$ \\
\hline Standard VH-mode & $1.3 \times 10^{6}$ & 0.48 & 1.2 \\
Hi ch $\ell_{\mathrm{i}}$ VH-mode & $1.1 \times 10^{6}$ & 0.07 & 1.5 \\
High power VH-mode & $0.95 \times 10^{6}$ & 0.33 & 1.15 \\
\hline
\end{tabular}

Figure 4 illustrates the good agreement between the parameters of the reconstructed equilibrium just before the $\mathrm{VH}$-mode termination and the stability boundaries predicted by the GATO analysis. The figure shows the growth rate calculated for the $n=2$ mode using GATo, as a function of $J(\rho \approx a)$ and $P^{\prime}(\rho \approx a)$. The values for the reconstructed experimental equilibrium are indicated by the solid point in the figure. The experimental equilibrium is located at the stability boundany. Increasing either $J(\rho \approx a)$ or $P^{\prime}(\rho \approx a)$ results in a rapid increase in the predicted growth rate. Decreasing $P^{\prime}(\rho \approx a)$ results in instability to an internal mode as $P^{\prime}(\rho \approx 0)$ increases to compensate for decreasing $P^{\prime}(\rho \approx a)$ while keeping $\beta_{N}$ constant [7].

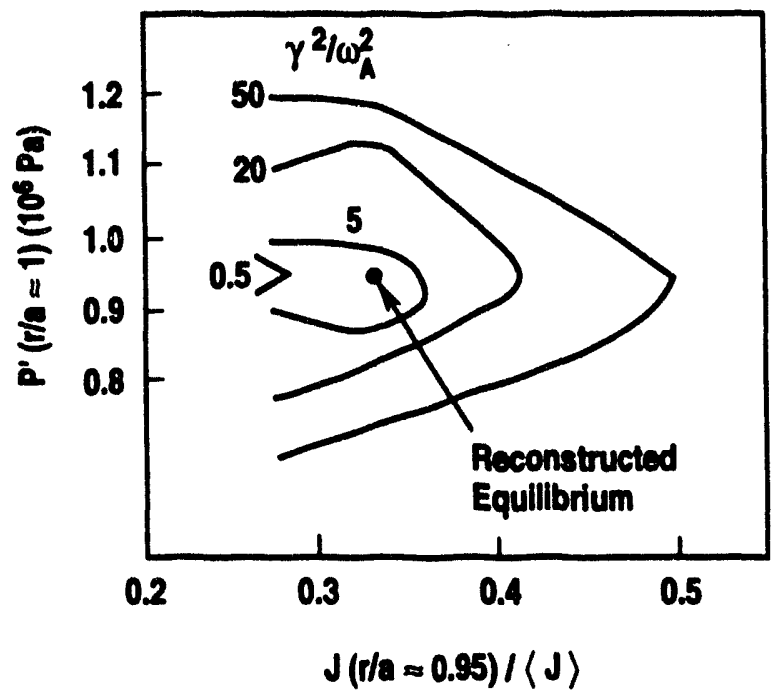

Fig. 4. Contours of constant value of normalized growth rate for the $n=2$ mode for parameters similar to the "high power" discharge in Table I.

In summary, increasing the edge current density self-consistently with the edge pressure gradient by improving the edge thermal barrier in VH-mode can result in instability at relatively low values of $f_{N}$. In addition, evidence has been presented from both $\mathrm{H}$-mode and $\mathrm{VH}$-mode discharges that shows that active reduction of the edge current density can result in a reduction in confinement, either by loss of the $\mathrm{H}$-mode pressure pedestal or by inhibiting the transition to the improved confinement VH-mode regime. These results suggest that instead of active reduction of the edge current density, control of the central portion of the current density profile should be utilized to maintain low- $n$ stability in the presence of high values of the edge pressure gradient and current density, as proposed in Ref. 8.

\section{REFERENCES}

[1] J.R. Ferron et al., Phys. Fluids B 5, 2532 (1993) and references listed there.

[2] L.L. Lao et al., Phys. Rev. Lett. 70, 3435 (1993).

[3] W. Howl et al., Phys. Fluids B 4, 1724 (1992).

[4] L.L. Lao et al., Phys. Fluids B 4, 232 (1992).

[5] T.H. Osborne et al., "Confinement and stability of VH-mode discharges in the DIII-D tokamak" (submitted to Nucl. Fusion) and references listed therein.

[6] T.S. Taylor et al., in Plasma Physics and Controlled Nuclear Fusion Research 1990 (IAEA 1991), Vol. I, p. 177.

[7] E.J. Strait, in Proc. 20th EPS Conference on Controlled Fusion and Plasma Physics (1993), Part I, p. 211.

[8] T.S. Taylor et al., this conference. 

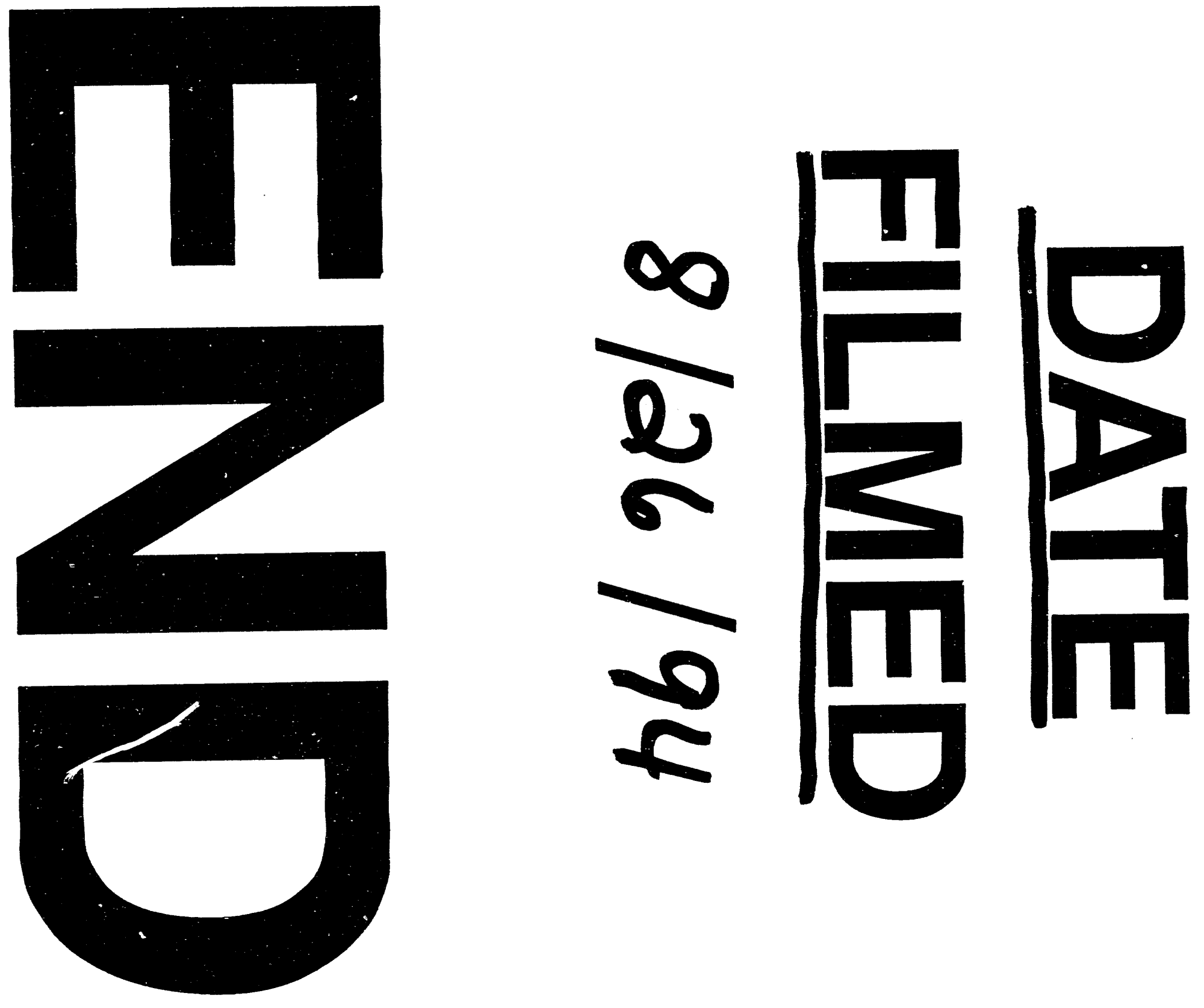


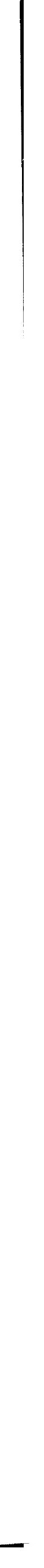

